ISAHP Article: Kashi, Franek/AHP in Personnel Management: Can the Key Competencies Change with Company's Strategy? International Symposium of the Analytic Hierarchy Process 2014, Washington D.C., U.S.A.

\title{
AHP IN PERSONNEL MANAGEMENT: CAN THE KEY COMPETENCIES CHANGE WITH COMPANY'S STRATEGY?
}

\author{
Katerina Kashi \\ Faculty of Economics \\ VSB-Technical University of Ostrava \\ Ostrava, Czech Republic \\ E-mail: katerina.kashi@vsb.cz \\ Jiri Franek \\ Faculty of Economics \\ VSB-Technical University of Ostrava \\ Ostrava, Czech Republic \\ E-mail: jiri.franek@vsb.cz
}

\begin{abstract}
Main aim of this paper is to determine key competencies for a top manager in an automotive company. Firstly, the authors deal with the description of competency models, its development and utilization. After, the authors illustrate how the competencies can be decomposed so that AHP can be used for its evaluation. Then individual competencies are ranked. Further, the authors compare the current key competencies ranking with results from last year. At the conclusion of this article, the authors are dealing with the research's results and discussion.
\end{abstract}

Keywords: AHP, analytic hierarchy process, competency models, key competencies 
ISAHP Article: Kashi, Franek/AHP in Personnel Management: Can the Key Competencies Change with Company's Strategy? International Symposium of the Analytic Hierarchy Process 2014, Washington D.C., U.S.A.

\section{Introduction}

In today's competitive world it is very important to build on the competitive activities of business. Companies today have to think about their business strategy, especially when it comes to the kind of competencies a business needs to have in order to compete in a specific environment. Competency models, which should be designed for all key positions in the company, show what competencies are necessary for individual position. The question is what the key competencies in each position are and can they change according to company's strategy?

\section{Literature Review}

To be able to determine the key competencies the method analytic hierarchy process (AHP) can be used. AHP method is a technique which enables us to organize and analyze complex decisions. The AHP helps the decision makers find one that best suits the goal and their understanding of the problem. The method provides rational framework to structure a decision problem, to represent and quantify its elements, which relate to those elements of the overall goal, and to evaluate alternative solutions. This method is suitable for the competency modeling because of the possibility to decompose the goal/objective to several criteria and sub criteria, Saaty (1994), Saaty and Peniwatti (2007). Hsiao et. al. (2011) used analytic hierarchy process to analyze selection criteria for recruitment of five different roles in the area of information system. Whereas, Zolfani et. al. (2012) perceived selection of new employees or group of employees as a fundamental problem in the human resources area. In this study the AHP method was used to identify which criteria are important when selecting a new team member. Then the TOPSIS method was applied to evaluate the alternatives.

\section{Hypotheses/Objectives}

The objective of this paper is to present a competency model where group of competencies and individual competencies are ranked according to importance and to determine key competencies for a top manager. The evaluation by AHP will be executed in an automotive company. The evaluation of competencies will be done by five experts in the company and they will decide in consensus on the competencies preferences. The results will then be compared with last year results in order to see if the change of company's strategy can change the ranking of key competencies. The hypothesis is that the key competencies will slightly change with the company's strategy.

\section{Research Design}

Based on the results from the author's previous research executed in 2011, where employees of one manufacturing company located in the Czech Republic were asked about the satisfaction with the performance appraisal system and the choice of evaluated competencies, the following competencies were mentioned the most often: work with information, problem solving, leadership, change management, effective communication, active listening, negotiating, team cooperation, motivating others, relevant professional knowledge, business knowledge, strategic thinking, analytical thinking, proactivity, creativity, mental agility and emotional resilience. To be able to identify key competencies, one position (the top manager) was chosen for this illustration. The evaluation was executed via interview and the company's experts i.e. company's HR 
ISAHP Article: Kashi, Franek/AHP in Personnel Management: Can the Key Competencies Change with Company's Strategy? International Symposium of the Analytic Hierarchy Process 2014, Washington D.C., U.S.A.

manager, financial manager, production manager, quality manager and CEO decided about the preferences for each pair.

\section{Data Analysis}

Proposal of the decomposition of competencies for the utilization of AHP is shown in the following figure.

Figure 1: The decomposition of competencies for the utilization of AHP

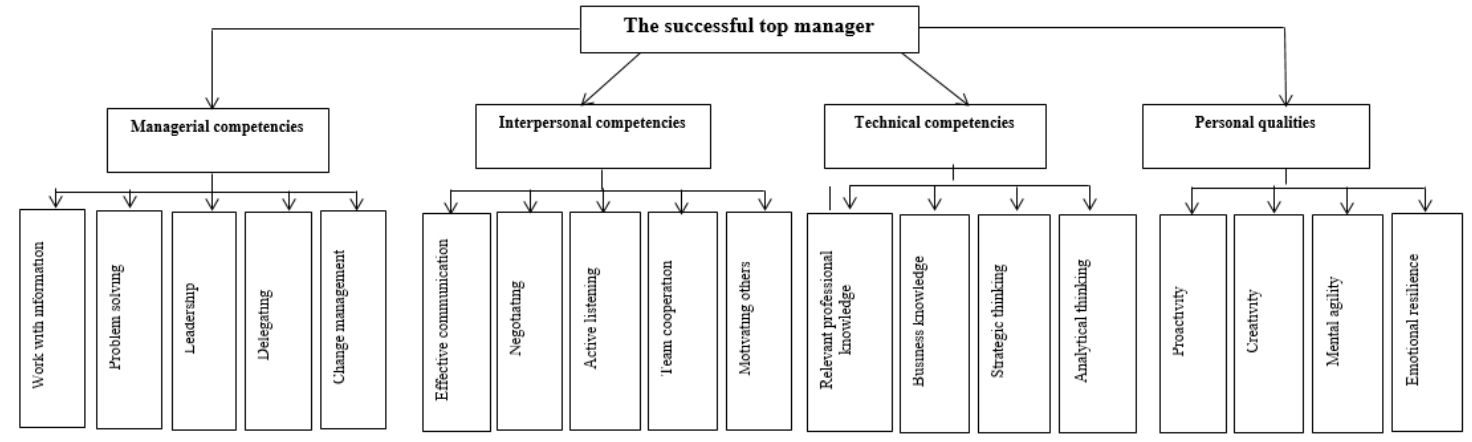

Source: Author's elaboration

The expert's assessed the criteria based on the following information. The assessor assigned the following values if the row was preferred before a column: A - the elements are indifferent, $\mathrm{B}$ - there is a slight preference, $\mathrm{C}$ - there is a strong preference, $\mathrm{D}$ - there is a very strong preference, $\mathrm{E}$ - there is an absolute preference. If the column was preferred before a row the reciprocal values were assigned, e.g. 1/A, 1/B, 1/C, 1/D, 1/E. The letter evaluation was intentionally proposed by the authors to eliminate the problem of assigning an average number to all comparisons. An example is shown for the first level of the decomposition in the following table 1 .

Table 1 Pair-wise comparison table

\begin{tabular}{|l|c|c|c|c|}
\hline Objective & Managerial & Interpersonal & Technical & Personal \\
\hline Managerial & $\mathrm{A}$ & $\mathrm{B}$ & $1 / \mathrm{A}$ & $\mathrm{A}$ \\
\hline Interpersonal & 1/B & $\mathrm{A}$ & $1 / \mathrm{A}$ & $1 / \mathrm{A}$ \\
\hline Technical & & & $\mathrm{A}$ & $\mathrm{C}$ \\
\hline Personal & & & & $\mathrm{A}$ \\
\hline
\end{tabular}

\section{Limitations}

This study is limited by its execution within a particular company. However, the hypothesis is also limited to this company as well. The authors do not want to make conclusions for the whole domain of competency models but to suggest a way how HR analysts can apply AHP approach to their work process. Further research will be focused on different types of firms and positions. The limitation of the study can be also found in its longevity and scope. 
ISAHP Article: Kashi, Franek/AHP in Personnel Management: Can the Key Competencies Change with Company's Strategy? International Symposium of the Analytic Hierarchy Process 2014, Washington D.C., U.S.A.

\section{Conclusions}

The key competencies for a top manager have changed in the period of one year. All competencies ranking is shown in the following table. The hypotheses that the key competencies will change was correct. The company's key top manager's competencies in the beginning of 2013 were different than in the beginning of 2014. The reason is that the company's strategy has changed. In 2013 the company was manufacturing the usual products however in the end of 2013 many new lines were moved to the plant from another one, which is now closed. Therefore, the managerial competencies in 2014 are different because the managers now have to concentrate much more on leadership and change management then just on operational management.

Table 2 Ranking of competencies determined for a top manager position

Global weights of competencies for top manager

\begin{tabular}{rlrlr} 
Ranking & & $\underline{2013}$ & & $\underline{2014}$ \\
\hline 1 & Strategic thinking & $19.04 \%$ & Leadership & $14.90 \%$ \\
\hline 2 & Business knowledge & $13.30 \%$ & Strategic thinking & $14.28 \%$ \\
\hline 3 & Problem solving & $9.69 \%$ & Change management & $13.93 \%$ \\
\hline 4 & Work with info & $7.78 \%$ & Business knowledge & $9.98 \%$ \\
\hline 5 & Proactivity & $7.77 \%$ & Problem solving & $8.98 \%$ \\
\hline 6 & Mental agility & $6.83 \%$ & Delegating & $8.98 \%$ \\
\hline 7 & Professional knowledge & $6.76 \%$ & Professional knowledge & $5.07 \%$ \\
\hline 8 & Leadership & $5.01 \%$ & Negotiating & $4.28 \%$ \\
\hline 9 & Change management & $4.02 \%$ & Effective communication & $3.43 \%$ \\
\hline 10 & Analytic thinking & $3.66 \%$ & Analytic thinking & $2.74 \%$ \\
\hline 11 & Negotiating & $3.23 \%$ & Proactivity & $2.60 \%$ \\
\hline 12 & Stress resilience & $3.00 \%$ & Mental agility & $2.29 \%$ \\
\hline 13 & Effective communication & $2.59 \%$ & Active listening & $2.21 \%$ \\
\hline 14 & Delegating & $2.08 \%$ & Work with info & $2.09 \%$ \\
\hline 15 & Active listening & $1.67 \%$ & Motivating others & $1.78 \%$ \\
\hline 16 & Creativity & $1.52 \%$ & Stress resilience & $1.01 \%$ \\
\hline 17 & Motivating others & $1.34 \%$ & Team cooperation & $0.92 \%$ \\
\hline 18 & Team cooperation & $0.69 \%$ & Creativity & $0.51 \%$ \\
\hline & & & & \\
\hline & & & \\
\hline
\end{tabular}

\section{Key References}

Mertins, K., Wuscher, S., Will, M. (2011) Germany - Towards a Knowledge-Based Economy In: Proceedings Of The 12th European Conference On Knowledge Management Vols 1 And 2, 2011, eds. Lehner, F., Bredl, K., pp 626-636.

Hsiao, WH et al. (2011). Selection criteria of recruitment for information systems employees: Using the analytic hierarchy process (ahp) method. African Journal of Business Management, 5(15), 6201-U209. 
ISAHP Article: Kashi, Franek/AHP in Personnel Management: Can the Key Competencies Change with Company's Strategy? International Symposium of the Analytic Hierarchy Process 2014, Washington D.C., U.S.A.

Saaty, T. L.: Fundamentals of Decision Making and Priority Theory with the Analytic Hierarchy Process. RWS Publications, Pittsburgh, 1994. ISBN 13-978-0-9620317-6-2.

Saaty, T. L., K. Peniwatti and J. S. Shang. The analytic hierarchy process and human resource allocation: Half the story. Mathematical and Computer Modelling. 2007, roč. 46, 7-8, 1041-1053. Available at: http://linkinghub.elsevier.com/retrieve/pii/S0895717707000842.

Zolfani, SH, Antucheviciene, J . (2012). Team member selecting based on ahp and topsis grey. Inzinerine Ekonomika-Engineering Economics Volume: 23 Issue: 4 Pages: 425434 DOI: 10.5755/j01.ee.23.4.2725 , 23(4), 425-434. doi: 10.5755/j01.ee.23.4.2725. 